\title{
REVIEW-TYPE CHAPTER
}

The maize in planta haploid induction lines, a corner stone for doubled haploid technology

Nathanaël M.A. Jacquier ${ }^{1,2}$, Laurine M. Gilles ${ }^{2}$, Jean-Pierre Martinant ${ }^{2}$, Peter M. Rogowsky ${ }^{1}$ and Thomas Widiez ${ }^{*}$

${ }^{1}$ Laboratoire Reproduction et développement des Plantes, Univ Lyon, ENS de Lyon, UCB Lyon 1, CNRS, INRAE, F-69342, Lyon, France.

${ }^{2}$ Limagrain, Limagrain Field Seeds, Research Center, F-63360 Gerzat, France.

* Corresponding author. Tel: +33 472728608. e-mail: thomas.widiez@ens-lyon.fr

Running head: maize in planta haploid induction

PMID: 34270003 DOI: 10.1007/978-1-0716-1335-1 2 
i. Chapter Title: The maize in planta haploid induction lines, a corner stone for doubled haploid technology

\section{ii. Abstract}

Doubled Haploid (DH) technology produces strictly homozygous fertile plant thanks to doubling the chromosomes of a haploid embryo/seedling. Haploid embryos are derived from either male or female germ line cells and hold only half the number of chromosomes found in somatic plant tissues, albeit in a recombinant form due to meiotic genetic shuffling. DH production allows to rapidly fix these recombinant haploid genomes in the form of perfectly homozygous plants (inbred lines), which are produced in two rather than six or more generations. DH breeding enables fast evaluation of phenotypic traits on homogenous progeny. While for most crops haploid embryos are produced by costly and often genotype-dependent in vitro methods, for maize, two unique in planta systems are available to induce haploid embryos directly in the seed. Two "haploid inducer lines", identified from spontaneous maize mutants, are able to induce embryos of paternal or maternal origin. Although effortless crosses with lines of interest are sufficient to trigger haploid embryos, substantial improvements were necessary to bring DH technology to large scale production. They include the development of modern haploid inducer lines with high induction rates (8-12\%), and methods to sort kernels with haploid embryos from the normal ones. Chromosome doubling represents also a crucial step in the DH process. Recent identification of genomic loci involved in spontaneous doubling opens up perspectives for a fully in planta $\mathrm{DH}$ pipeline in maize. Although discovered more than 50 years ago, maize haploid inducer lines still make headlines thanks to novel applications and findings. Indeed, maternal haploid induction was elegantly diverted to deliver genome editing machinery in germplasm recalcitrant to transformation techniques. The recent discovery of two molecular players controlling haploid induction allowed to revisit the mechanistic basis of maize maternal haploid induction and to successfully translate haploid induction ability to other crops.

iii. Key words: Maize, haploid, haploid inducer line, embryo, gynogenesis, fertilization, seed development. 


\section{Introduction}

Haploid plantlets are characterized by a single set of chromosomes instead of the classical situation with two sets of chromosomes, one from the male and one from the female parent. A doubled haploid (DH) is literally an organism whose haploid genome has been duplicated, thus recovering the usual ploidy state of the species (diploid, tetraploid, hexaploid, etc.) necessary for achieving fertility (Figure 1; see Chapter 1). The main interest of DH plants is their perfect homozygosity. This implies that agriculturally interesting characters observed on a DH plant will be transmitted in a uniform manner to all its offspring. DH plants provide thus a rapid way to fix characters, making them particularly interesting for both genetic and breeding studies (see Section 2). DH technology requires three main steps: (1) the generation of a haploid, (2) detection of haploid embryos/plantlets, and (3) restoration of the ploidy level through chromosome doubling (Figure 1). This chapter will present the powerful capacities of maize to induce haploid embryos in planta, thanks to so called "haploid inducer lines" (or "inducer lines"; see Chapter 1). Although these original haploid induction systems arose spontaneously in maize, their efficiency was improved, thanks to breeding, to meet DH technology needs for industrial breeding $[1,2]$.

The occurrence of haploid individuals was first reported in 1922 among offspring of the diploid flowering plant Datura after cold treatment [3]. It was only 3 decades later that Chase pointed out for the first time the value of maternal maize haploids for use in breeding programs and genetic studies [4]. Modern DH programs use either in vitro or in vivo methods to generate haploid plants (see Chapter 1). The in vitro approach generally relies on the regeneration of plantlets from gametophytic tissues, i.e. microspores from anthers and egg cells from ovules to produce paternal and maternal haploids, respectively (see Chapter 1). Even though in vitro methods are used in a wide range of crops and represent the only available method for quite a few of them (see Chapter 2) $[5,6]$ they have the main disadvantage of being strongly dependent on the genotype, thus limiting their uses.

Maize DH programs used for a long time both in vitro (see Chapter 31) and in planta haploid induction methods, but at the dawn of $21^{\text {st }}$ century, the in planta approach based on haploid inducer lines clearly started to dominate [6]. In these in vivo methods, only a simple pollination of the line of interest by the inducer line is enough to obtain haploid embryos [2, 6-8]. Two types of haploid inducer lines are available in maize to generate paternal and/or maternal haploid 
1) In planta haploid embryo induction

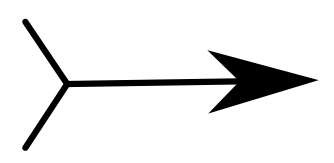

haploid embryo
2) Haploid plantlet

detection
3) Chromosome

doubling of haploid
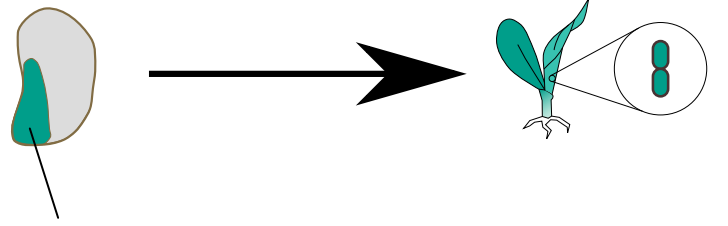

haploid plantlet

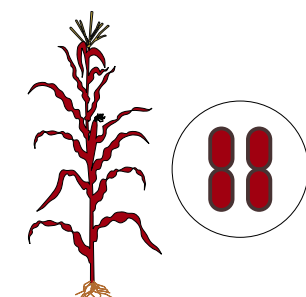

Doubled haploid DH 
embryos $[9,10]$. The following sections will describe (1) the multiple applications of maize haploid inducer lines, (2) the restoration of ploidy (i.e the genome doubling step) and especially recent advances in spontaneous doubling in maize, and (3) novel insights in the pathways operating in maternal haploid inducer lines with a highlight on recently identified molecular players.

\section{Current and future applications of maize DH technology}

The most important feature of DH technology is the creation of perfectly homozygous individuals, which have two (or more, in polyploid species) identical alleles at all loci. DH plants harbor a fixed genome and after self-pollination their offspring will constitute a uniform population. This feature has been exploited in many ways in genetic research and plant breeding.

\subsection{Use of maize DH in genetic studies}

The basis of applied genetic studies is to correlate genotype and phenotype. Accurate doubling of unique alleles in DHs rapidly reveals desirable as well as deleterious alleles [11]. Therefore, the easy and accurate fixation of genomes makes DH lines particularly efficient in a wide range of genetic approaches: identification of genes responsible for a given character, gene stacking, marker identification, quantitative trait loci (QTL) analysis, linkage disequilibrium studies, epistasis studies, and the development of genetic maps [12, 13]. Examples of DH use for QTL analysis are the identification of genomic regions involved in resistance to European corn borer [14], drought tolerance [15] or forage quality [16]. Regarding the use of DH plants in genetic fixation and backcross programs, Lübberstedt and Frei (2012) showed that the interest of this approach increases with the number of genes to be introgressed into the recipient germplasm [17]. Backcross programs are particularly interesting in scientific studies for the creation of near isogenic lines (NILs) which allow to compare the effect of different alleles for a given locus in the same genetic background. But backcross schemes are also important in plant breeding as explained next.

\subsection{Use of maize DHs for breeding F1 hybrids}

Since Chase's work during the late 40's [18, 19], DH technology has been used for the creation of homozygous inbred lines (Figure 2). F1 hybrids are derived by crossing two genetically different inbred lines. F1 hybrids display "hybrid vigor" or heterosis, i. e. a superior phenotype relative to 
either inbred parent [20], which is especially significant for maize inbred lines belonging to different heterotic groups [21].

Hybrid development requires two main steps: (1) development of inbred lines and, (2) crosses of selected parents to generate hybrid seed. DH technology represents a significant shortcut for the first step, since it allows the obtaining of pure inbred lines in 2 generations instead of the 4 to 8 generations of self-crossing in conventional breeding schemes such as single-seed descent (SSD) $[1,7,22]$ (Figure 2). Importantly, DH breeding enables early evaluation of phenotypic traits on homogenous progeny. Earlier phenotypic selection could even be done of the first DH plants (and not their progenies) for simple trait such as disease resistance. In planta maternal haploid induction is usually done on a highly heterozygous plant (which could be a F1 hybrid) with shuffled alleles presenting valuable traits (Figure 2). The resulting maternal haploid plants have thus unique but distinct combinations of different alleles from this interesting parent due to recombination and segregation during female meiosis. Chromosome doubling allows for fixation of the advantageous trait. The use of molecular markers and genomic selection allows now to select the desired genetic combination and to make yield potential predictions in order to identify the best DH candidate lines to be used as inbred lines. Additionally, DH breeding permits higher exploitation of genetic variability and is less subjected to selection bias during the process compared to the SSD method [22]. Whereas in maize DH lines are used as parents for commercial hybrids, in other species DH lines can be directly commercialized as cultivars.

\subsection{Use of maize DH for cytoplasmic male sterility transfer}

Cytoplasmic male sterility (CMS) refers to male sterility (non-functional pollen) caused by mitochondrial DNA mutation [23]. Since mitochondria are usually inherited from the female, CMS is maternally inherited. Hybrid seed production at field scale requires inbred females to be emasculated in order to prevent self-fertilization and to ensure crosses with the male inbred line. CMS of the female parent circumvents the need for manual or mechanical emasculation [24]. In addition, in order to restore the fertility in hybrids, the male parent has to carry fertility restoration gene(s) [24, 25]. To streamline CMS-based hybrid breeding, DH technology could be useful to rapidly transfer the "sterilizing cytoplasm" to a genetic background of interest. Indeed, CMS is classically transferred through multiple rounds of backcrossing. The use of a maize haploid inducer line (based on the ig1 mutation, see Section 3.1) [10], triggers paternal haploid 
Season 1 $\sim 6$ month

Season 2

Season 3 to 6 (up to 10)
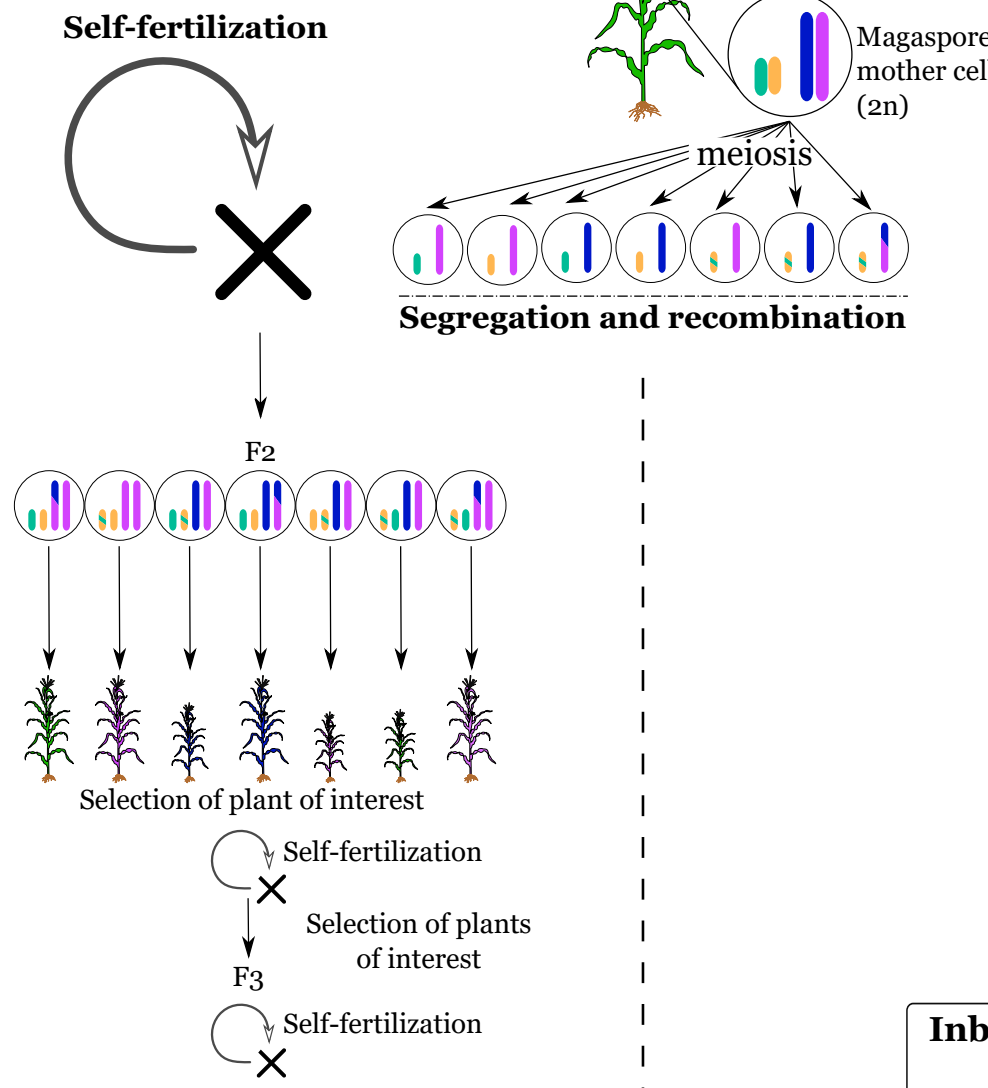

Selection of plants of interest

F6 (up to $\mathrm{F}_{10}$ )

Inbred lines with fixed genome

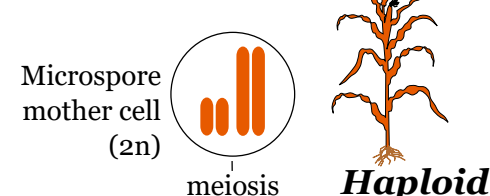

Haploid

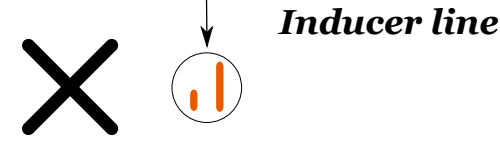

Maternal haploid induction

$\downarrow$

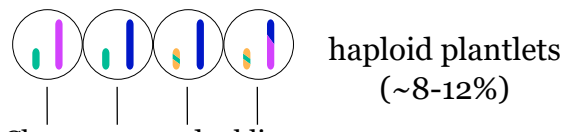

Chromosomes doubling

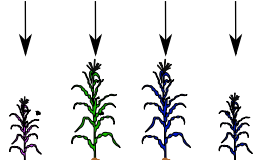

Selection of DH of interest (Do)

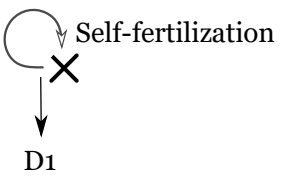

Inbred lines with fixed genome 
embryos with maternal cytoplasm. It thus provides one-step CMS conversion and greatly simplifies CMS-based hybrid breeding.

\subsection{Maize genome editing in recalcitrant lines using DH technology}

Genome editing provides a means to precisely modify genomes of living organisms, especially thanks to the CRISPR/Cas9 system, which is efficient and easy to use [26, 27]. In plants, however, delivery of the CRISPR/Cas9 editing machinery is often an obstacle for efficient genome editing. Indeed, delivery is conditioned by the ability to transform the species of interest and to regenerate plants from tissue culture [28]. In the case of maize it is especially challenging to edit a desired genotype/line, because numerous maize germplasms are recalcitrant to genetic transformation and/or regeneration [29]. Haploid inducer lines were recently used by two groups to overcome this problem and to edit recalcitrant germplasm [30, 31]. The transgenic editing cassette is introduced into the haploid inducer lines by direct transformation if possible or by introgression from a transformable line. Pollen from this transgenic haploid inducer is then used to fertilize and directly edit elite germplasm. In the proofs of concept reported, only a small proportion $(\sim 3 \%)$ of maternal haploid embryos generated were found to be edited [30,31]. Subsequent genome doubling then leads directly to DH plants homozygous for the desired edits. In addition, the edited plants do not contain the transgene that provoked the editing, since the paternal genome is lost during the haploid induction process. Since the molecular mechanism behind maize haploid induction has still some unknowns (see Section 4.2) [6], it remains unclear whether the sperm cell delivered directly the CRISPR machinery (Cas9 protein and sgRNA) into the egg cell, or it was transcribed and translated from the transgenic paternal genome within the egg cell before being eliminated/lost [6]. To sum-up, the advantages of using haploid-inducer lines to mediate genome editing are: (1) any maize genotype can be edited, (2) the editing cassette is lost directly in the first generation of the edited plant, and (3) edited alleles are homozygous due to DH technology.

\section{Maize DH technology step by step}

The implementation of an in planta haploid induction system in DH breeding programs requires three critical steps: (1) a good haploid inducer line to generate sufficient haploids embryos, (2) a 
reliable method to detect haploids among the offspring, and (3) an efficient way to double chromosomes of haploids plantlets (Figure 1).

\subsection{Maize haploid inducer lines}

In planta haploid induction consists of the production of viable seeds that contain haploid embryos, triggered by intraspecific crosses using a so-called haploid inducer line (see chapter 1). Haploid inducer lines are limited to a handful of species (see Chapter 1) [6, 32], and maize has a prominent position since two types of haploid inducer lines were found during the longstanding history of maize genetic research:

(1) A maize haploid inducer line (stock- 6 ) which produces haploid embryos of maternal origin, i.e having solely the maternal genome [9]. This line is used as male parent in the crosses.

(2) A maize haploid inducer line (indeterminate gametophyte 1) which produces haploid embryos of paternal origin (although some haploid embryos with maternal origin are also produced), i.e. having solely the paternal genome, but maternal cytoplasm [10]. This line is used as female parent in the crosses.

Historically, the first spontaneous maternal haploid embryo was reported in maize [33]. It was only 15 years later that Chase proposed how this developmental defect could be exploited as DH in breeding [19]. Chase reported a spontaneous maternal haploid production at a frequency of $0.1 \%$ in some maize germplasms [4]. Despite some commercial success in breeding [11], the low spontaneous haploid induction frequency severely limited the spread of DH technology at this period. The true birth of maize haploid inducer lines dates to 1959, when Ed Coe reported that stock-6 was able to induce about 2-3\% of maternal haploids [9]. Further breeding of stock-6 permitted the selection of lines with higher induction rate, with an average of $8 \%$ for RWS for instance [34-36]. Regarding the ability to induce paternal haploid embryos, this property was discovered during the phenotypic characterization of the igl mutant [10]. The igl haploid inducer line presents a relatively low haploid induction rate of $\sim 3 \%$ and is quite variable depending on the genetic background [37]. In conclusion, maternal haploid production represents presently a very widely used tool in maize breeding, whereas paternal haploid embryos could be used for CMS conversion (see Section 2.3). 


\subsection{Haploid embryo/plant detection}

A major bottleneck for large-scale production of DH lines using the in vivo haploid induction methods is the ability to quickly and accurately identify the small fraction of haploid embryos/plants among a large fraction of diploid embryos/plants in progenies deriving from crosses with haploid inducers. Haploid maize plants display some morphological features distinguishing them from diploid plants, for example smaller coleoptile and leave sizes, shorter plant height, lower kernel weight, sterility or even shorter stomatal guard cell length $[9,23,38$ 41]. However, discrimination upon morphological aspects is imprecise, depends on the environment and genetics, slows down high-throughput applications and represents nonnegligible cost. Flow cytometry and genotyping are the two most reliable methods even though they are not routinely used because of their labor-intensive and costly protocols [41]. To remedy this limitation, methods using genetic markers have been developed and are now widely used for industrial scale DH production. Even if efficient haploid identification can be done by the human eye using recessive mutations like liguleless and glossy, causing respectively a lack of the ligule on leaves and a cuticle defect of juvenile leaves [9, 42], these detection methods are limited to basic science because they require the prior introgression of the respective mutations in lines of interest. A more recent system used by academia is based on the use of two different fluorescent proteins, one specific to the endosperm and the other to the embryo, making it possible to easily identify haploid kernels, but remaining limited due to the transgenic nature of the inducer [43].

In industrial DH production, haploid detection is commonly performed using the dominant color marker R1-navajo introduced in numerous modern inducer lines. This marker confers purple/red pigmentation of the tip of the aleurone layer of the endosperm and the scutellum of the embryo. In offspring resulting from a cross with a male inducer, pigmentation of the aleurone and nonpigmentation of the embryo indicate a kernel with putative maternal haploid embryo, identifiable by hand or using automated technologies $[44,45]$. However, despite its interest and its widespread present use, this approach is limiting for some genetic maize backgrounds which interfere with the color readout $[36,46]$. To overcome this limitation, other dominant color makers were harnessed, such as P11 (Purple1), conferring red pigmentation in roots [47]. Another method to detect haploids is based on the quantification of the oil content of the embryo coupled with the use of specifically bred high oil inducer lines [48]. Diploid embryos contain more oil than haploid embryos due to the presence of the high oil trait from the paternal genome in diploid 
embryos. First mentioned by Rotarenko et al. in 2007, the proof of concept and further developments to meet high throughput requirements came a few years later [49, 50]. Melchinger et al (2013) developed a method to measure oil content of maize kernels by nuclear magnetic resonance (NMR) and to automatically identify haploid kernels at high throughput. This nondestructive method allows the sorting of a haploid/diploid kernel every three seconds with less errors than using the RI-nj color marker [50]. Additional studies supported this concept developing or improving similar technology to move towards high-volume selection process [51, 52]. Near infrared spectroscopy (NIR) and hyperspectral imaging technology has also been used to select single haploid kernels based on composition and pigmentation, and begins to be transposed to selection based on oil content $[51,53]$.These different methods offer efficient and high-speed identification of maize kernels containing haploid embryos, making in planta haploid induction viable for industrial DH production.

\subsection{Genome doubling of haploids}

Haploid plants can be grown, but are less vigorous than their diploid counterparts: they have thinner leaves, shorter size and are usually sterile (gametes are non-viable) because of meiotic defects $[18,54,55]$. The chromosomes of haploid plants must be doubled to restore fertility. Two types of chromosome doubling methods exits: artificial chromosomal doubling using chemical treatment, or spontaneous chromosomal doubling.

\subsubsection{Artificial doubling of haploids}

Almost as early as haploids were discovered, colchicine, a cell division inhibitor, was used to artificially replicate DNA without or with defective cytokinesis, resulting in chromosome duplication without cell division, and thus in diploid restoration when used on haploid cells [56]. By immersing haploid seedlings in colchicine solution, between 0 to $40 \%$ of them will have restored fertility, and therefore can be used for self-fertilization [54]. Although colchicine treatment is at present frequently used, it has several drawbacks. Firstly, it is highly toxic and can cause environmental and health issues [57]. Secondly, at higher doses it is also phytotoxic and regularly a considerable number of putative haploids is lost during colchicine treatment [54]. Nevertheless, phytotoxicity can be reduced by modifying protocols for chromosomes doubling [58] (see Chapter 9). The hazardous characteristics of colchicine might be overcome thanks to other chemicals like amiprophosmethyl (APM) or pronamid, which have been shown to display rather good doubling properties at concentrations lower than those of colchicine, combined with a 
reduced toxicity on animals [57, 59]. Physical treatments, in general, present interesting alternatives such as the use of nitrous oxide gas in particular, as this gas is considered safe and provides doubling results close to colchicine [60].

\subsubsection{Spontaneous haploid genome doubling (SHGD)}

Another strategy to tackle colchicine limitations is through the improvement of spontaneous doubling methods. SHGD is commonly measured as haploid male fertility (HMF) because this trait is the most critical component of haploid fertility [55, 61-63]. Indeed, in most maize germplasm, spontaneous chromosome doubling occurs at high frequency (above 90\%) in female reproductive organs, whereas the frequency is only between 0 to $20 \%$ in male organs $[64,65]$. Therefore, recovery of male fertility is the key factor for SHGD. Recent advances in mapping QTLs implicated in SHGD are particularly interesting [55, 61, 63, 66]. Indeed, several QTLs with additive effect were identified and are distributed across the 10 maize chromosomes [61, 63, 65, 67]. Exploiting the SHGD trait in DH breeding schemes constitutes an exciting step forward to move maize DH technology towards a full in planta process, at least for certain maize lines [68]. In a future time, knowledge of the genes and mechanism involved in SHGD could be combined with the trans editing tool offered by in planta haploid inducer lines (see Section 2.4). Haploid inducer lines could then simultaneously trigger haploid induction and deliver the editing machinery to (i) edit a trait of interest and (ii) create a favorable allele for SHGD directly in the haploid embryo. However, the presently low proportion of edited haploids needs to be improved for efficient co-editing. Consequently, prior introgression of SHGD QTLs in the source germplasm used in breeding programs seems more realistic at this stage, even though the deleterious effect of such introgression has to be assessed.

\section{Towards the identification of mechanisms that trigger maize in planta haploid induction}

The discovery of the two types of maize haploid inducer lines started more than 50 years ago [9, 10]. Consequently, there is a wealth of literature trying to puzzle out the genetic tricks behind maize haploid inducer lines, especially regarding maternal haploid induction which is predominantly used in maize breeding. Since kernels having haploid embryos are products that deviate from the classical double fertilization of higher plants $[7,8]$, it is first necessary to briefly describe the events of double fertilization, which is characterized by two separate and parallel 
fusion events between male and female gametes (Figure 3). The haploid egg cell is fertilized by a first haploid male gamete and becomes the diploid embryo (Figure 3). The diploid central cell is fertilized by a second haploid male gamete from the same pollen tube to form a nutritive tissue, the triploid endosperm [69, 70] (Figure 3). The two male gametes which are named the sperm cells are delivered to the female embryo sac by the pollen tube that enters one of the two synergids [70]. In maize, the two sperm cells, coming from the same pollen grain, can fuse randomly to the egg or central cell [71]. In crosses involving haploid inducers lines, in addition to normal kernels with diploid embryos and kernels containing haploid embryos, many kernels abort or do not even develop due to different types of fertilization defects occurring in the two types of maize inducer lines [72-74]. A 2:1 balance of maternal and paternal genome in endosperm is crucial for correct seed development [75], which is not respected in certain outcomes of fertilization in an haploid inducing context and might explain kernel abortions.

\subsection{Mechanism behind maize paternal haploid embryo induction}

The induction of paternal haploid embryos has been reported to occur at a frequency of $3 \%$ in the inbred line Wisconsin-23 carrying the spontaneous mutation indeterminate gametophyte 1 (igl) (Kermicle, 1969, Kermicle,1971). In this situation, the haploid inducer line (igl mutant) is used as female parent: pollen from the male parent will provide the nuclear genome of the future $\mathrm{DH}$ whereas the inducer line provides the cytoplasm [10] (see Section 3.1). The igl mutation affects drastically the embryo sac by increasing the number of nuclear divisions before cellularization, which generates an indeterminate embryo sac with extra numbers of micropylar cell, synergids, egg cells, central cells and/or polar nuclei within central cells $[73,76,77]$. In addition to produce male and, to a lesser extent, female haploid embryos $(\sim 0.5 \%)$, the mutant displays other phenotypes such as a high ploidy level of endosperm ( $45 \%$ of the seed), $7 \%$ of heterofertilization (a double fertilization by sperm cell from two different pollens), $\sim 6 \%$ poly-embryony (several embryos in a unique seed), and aborted kernels [10, 72]. The igl mutation was cloned and $I G 1$ codes for a LATERAL ORGAN BOUNDARIES (LOB) domain transcription factor [73]. Despite the known identity of the causal gene, the cellular and molecular mechanism that lead to paternal haploid embryos in maize still remains obscure: hypothetic pathways and scenarios have been reviewed by Seguí-Simarro [78]. 


\subsection{Mechanisms behind maize maternal haploid embryo induction}

The maize maternal haploid induction system relies on a male gametophyte defect caused by a spontaneous mutation initially found in stock- 6 germplasm [9, 39, 79]. The fact that kernels presenting a haploid embryo have their neighboring endosperm fertilized [39, 79, 80], clearly indicates that fertilization by at least one of the two sperm cells is mandatory. Therefore, this process falls under the definition of in vivo gynogenesis, according to which at least one sperm cell is necessary for egg cell development into an embryo with exclusively maternal genetic information [6].

The initial observations of sperm cell morphology from stock-6-derived lines identified 5 types of pollen grains, two types of which presented a special interest: those having one sperm cell of normal size whereas the second sperm cell was either larger $(5.56 \%)$ or smaller $(0.76 \%)$ [81]. The authors noted that the sum of these two types was twice the induction rate (3\%) and concluded that defective pollen grains were outcompeted by normal pollen grains for fertilization. Alternatively, since defective sperm cells likely fuse randomly with either the egg cell or the central cell, the $3 \%$ of haploid embryos could reflect the situation when the "normal" sperm cell fuses with the central cell, whereas the defective sperm cell either fuses with the egg cell or otherwise triggers its autonomous development. A subsequent study went a bit further and suggested aneuploidy (unbalanced chromosome number) in some sperm cells [82]. Recently, single sperm cell nucleus sequencing confirmed the existence of aneuploidy and chromosome fragmentation in sperm cells of some pollen grains of inducer lines [83]. Three types of pollen grains were listed: (1) 65 to $84 \%$ of pollen harbored two normal sperm cells, (2) 11 to $15 \%$ had one normal and one aneuploid sperm cell, lacking and/or gaining some chromosomes and/or chromosome fragments and (3) in 5 to $20 \%$ of both sperm cells were aneuploid (Figure 3) [83]. Interestingly, these chromosome defects/aneuploidy were not found in the vegetative nucleus [83]. A time-course indicated that aneuploidy started to occur during the last steps of microgametogenesis (pollen maturation) around the second division [83]. Observations of defective sperm cells are compatible with the two main hypotheses historically discussed in the literature on mechanism leading to maternal haploid induction in maize (Figure 3): (1) fusion of a "defective" sperm cell with the egg cell followed by loss of the paternal inducer genome during early embryogenesis, (2) single fertilization of the central cell only leading to a functional endosperm that supports seed development and autonomous development of the unfertilized 

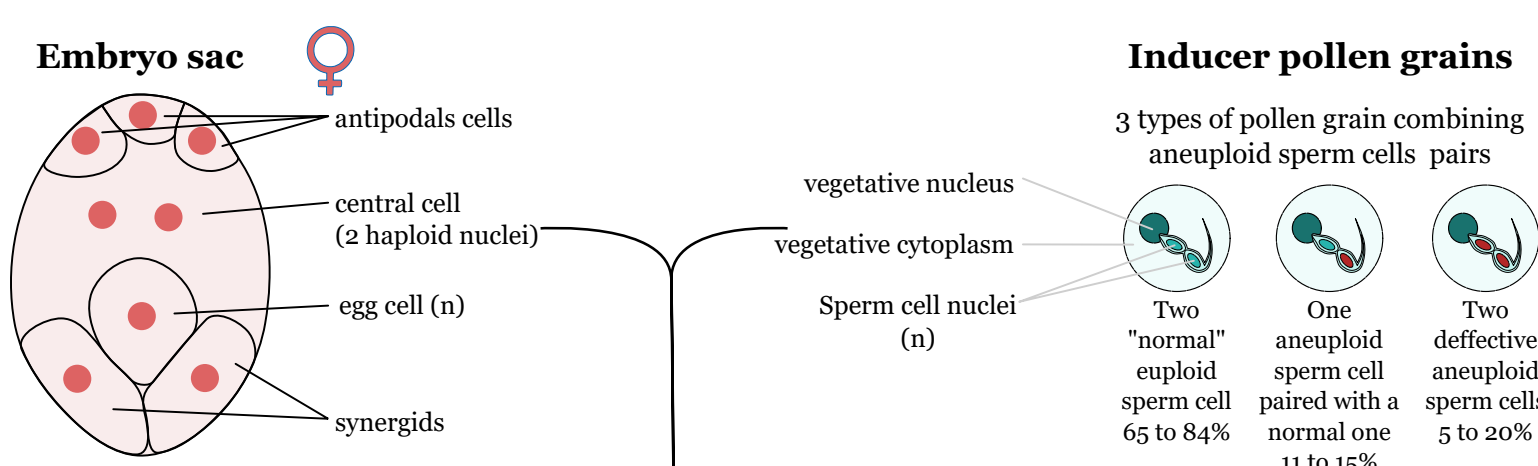

3 types of pollen grain combining aneuploid sperm cells pairs

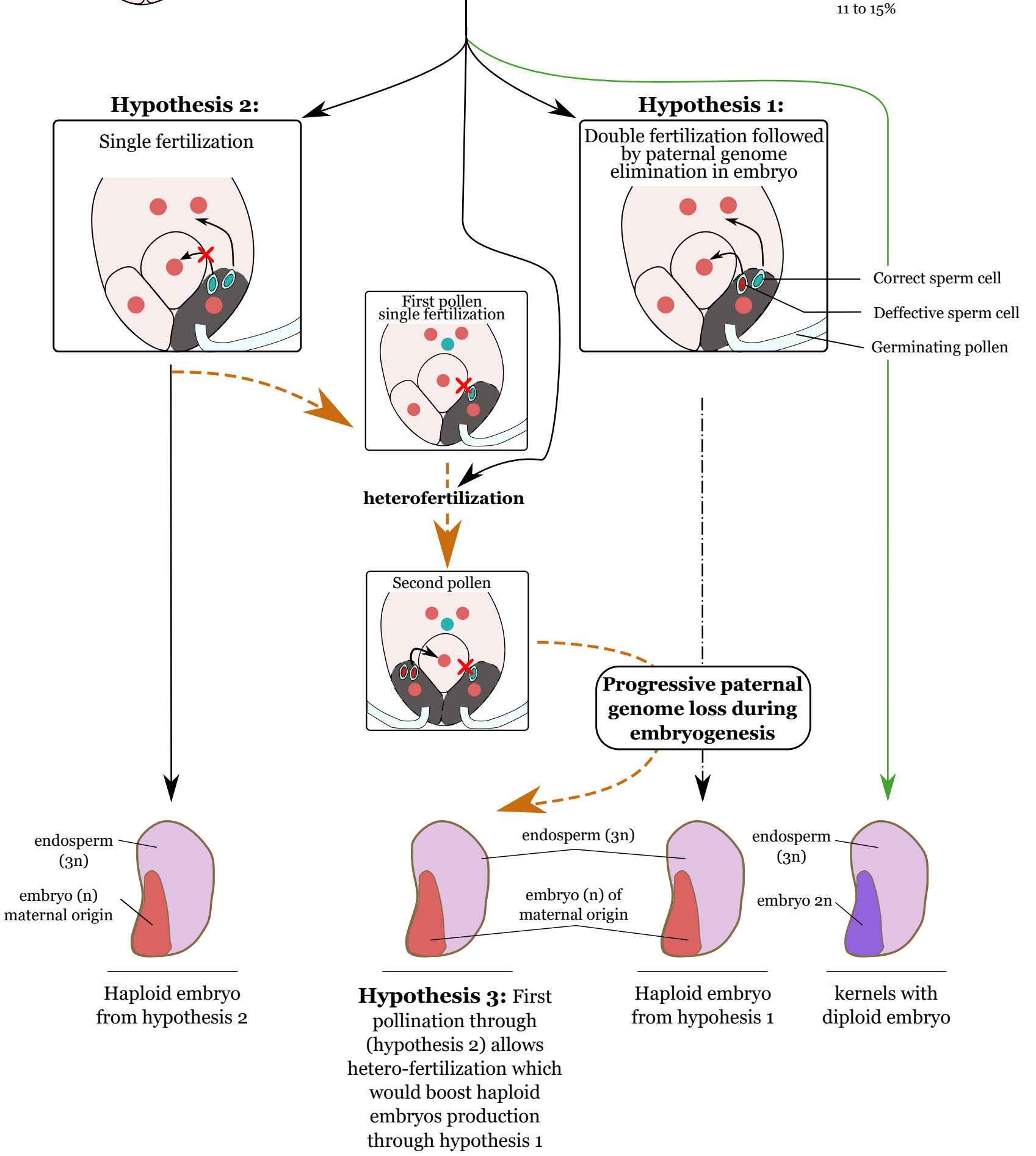

cell nucle

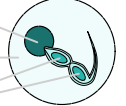

Two

"normal"

euploid
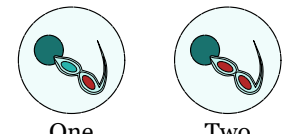

aneuploid deffective

sperm cell aneuploid

paired with a sperm cells

65 to $84 \%$ normal one 5 to $20 \%$

11 to $15 \%$ 
haploid egg cell into a haploid embryo. Quantitatively, only $1 \%$ to $10 \%$ of developed kernels carry haploid embryos $[34,79,84]$, which makes it difficult to study the phenomena.

Nevertheless, the recent identification of molecular players causing maternal haploid induction allows to propose new hypothetic mechanisms that unify the two previous historical hypotheses [6].

\subsubsection{Molecular players behind maize maternal haploid induction}

Maternal haploid induction in maize is a quantitative trait under the genetic control of multiple loci [79, 84]. One QTL, named gynogenesis inducerl (ggil) [79] or quantitative haploid induction rate 1 (qhir 1$)[84,85]$ has by far the strongest effect since it is responsible for $66 \%$ of the genotypic variance. The causal gene behind this ggil/qhir8 was cloned simultaneously by three independent groups and named NOT LIKE DAD (NLD), MATRILINEAL (MATL) and ZmPHOSPHOLIPASE-A1 (ZmPLA1) [86-88]. A 4bp insertion in the fourth exon of $N L D / M A T L / Z m P L A l$ was identified in the inducer line, causing a frameshift that adds 20 unrelated amino-acids prior to a premature STOP codon, and deletes the last 49 amino-acids. This mutation leading to a putative truncated version of the NLD/MATL/ZmPLA1 protein is found in every maize inducer line, and appears thus compulsory for haploid induction [86, 88]. The C-terminal region of NLD is thought to play a critical role in NLD/MATL/ZmPLA1 stability because mass spectral analysis did not detect the truncated protein in inducer pollen [87], and translational fusion of truncated NLD/MATL/ZmPLA1 with fluorescent protein did not allow its cellular visualization $[86,87]$. Gene editing confirmed that loss of function of NLD/MATL/ZmPLA1 induces haploid embryos [87, 88]. Confocal imaging of full length wildtype NLD/MATL/ZmPLA1 fused to fluorescent protein allowed to position NLD/MATL/ZmPLA1 protein either in cytoplasm [87] or both cytoplasm and plasma membrane of sperm cells [86], suggesting a role of this protein on sperm cell function. Phylogenetic analysis attributed NLD/MATL/ZmPLA1 to the protein family of patatin-like phospholipase A from group II [86]. Plant patatin-like phospholipases A are known to hydrolyze one of the two fatty acid chains contained in phospholipids or galactolipids [89]. Knowing the wide range of enzymatic activity of this type of enzyme [89-91], it is difficult to predict the in vivo substrate of NLD/MATL/ZmPLA1, although phospholipase A2 enzymatic activity has been confirmed by an in vitro assay [87]. Nevertheless, it may be speculated that loss of function of NLD/MATL/ZmPLA1 changes membrane composition and thereby plays a direct or indirect role 
on (1) membrane physical properties, (2) membrane lipid composition, or (3) lipid signaling. Interestingly, the onset of expression of $N L D / M A T L / Z m P L A 1$ during late pollen development correlates with the beginning of aneuploidy and the chromosome instabilities found in sperm cells [83]. The burning question is now to find the links between NLD/MATL/ZmPLA1 phospholipase activity and sperm cell genome instability.

A second QTL named quantitative haploid induction rate 8 (qhir8), explaining about $20 \%$ of genotypic variance, was identified [92]. Interestingly, the qhir8 locus alone induces very few haploid embryos $(\sim 0.15 \%)$, but it increases haploid induction rate by 2 to 6 fold in combination with the mutant allele at the NLD/MATL/ZmPLA1 locus [92, 93]. This synergistic effects indicates interaction between the underlying mechanisms and possibly even among gene products. The causal gene behind qhir8 is $Z m D M P$, standing for DOMAIN OF UNKNOWN FUNCTION 679 membrane protein family (DMP) [93]. CRISPR editing of $Z m D M P$ confirmed that the loss-of-function mutant caused the boosting effect when associated with the nld/matl/Zmpla1 mutation [93]. In pollen, ZmDMP showed enriched expression in the late stage as compared to early stages of pollen development [93]. Although plasma membrane localization was demonstrated for ZmDMP:GFP in a heterologous system, not much is known regarding its mode of action. Nevertheless, the knowledge gained on the two Arabidopsis thaliana orthologs AtDMP8 and AtDMP9 greatly helps to shed light on the probable action of ZmDMP in gamete fusion $[94,95]$. AtDMP8 and AtDMP9 are involved in double fertilization and gamete interactions [94, 95]. Loss-of-function mutants in Arabidopsis thaliana exhibited some fertilization failure, because unfused sperm cells were observed near female gametes. Despite $\sim 38 \%$ of normal double fertilization in the atdmp 8 atdmp 9 double mutant, $\sim 36 \%$ of the embryo sacs were found unfertilized, and most interestingly $\sim 24 \%$ of the embryo sacs presented a single fertilization of the central cell, with failure of sperm cell/egg cell fusion [94]. The remaining $2 \%$ corresponded to single fertilization of one sperm cell with the egg cell [94]. A similar role in sperm cell/egg cell fusion has not yet been directly demonstrated for ZmDMP in maize, but the fact that atdmp8 atdmp 9 double mutant is able to induce haploid embryos at low rate $(\sim 2 \%)$ in Arabidopsis, implies conserved function between maize and Arabidopsis [96]. It is thus tempting to speculate that impairment of ZmDMP function could lead to similar central cell single fertilization in maize, especially knowing that haploid inducer lines have been shown to provoke central cell single fertilization events $[97,98]$. If one considers that haploid embryos originate 
directly from these central cell single fertilizations and absence of sperm cell/egg cell fusion, this does not fit neither with the very low induction rate of zmdmp alone, nor with the synergistic effect of zmdmp and $\mathrm{nld} / \mathrm{matl} / \mathrm{zmpla} 1$ mutations. Additional mechanisms need to be invoked to explain the "boosting" effect of $z m d m p$ on haploid induction. Hetero-fertilization, which is a consequence of single fertilization because it represents the fusion of central cell and egg cell with sperm cells from two different pollen tubes, may provide an explanation for the synergistic interaction between $\mathrm{nld} / \mathrm{matl} / \mathrm{zmplal}$ and zmdmp (see Section 4.2.4) [6].

\subsubsection{Hypothesis of paternal genome elimination/loss}

One of the main mechanistic hypotheses to explain maternal haploid embryo induction is normal sperm cell fusion followed by paternal chromosome elimination during early embryogenesis (Figure 3; hypothesis 1) [80, 99-101]. Observations made in animal studies that revealed DNA damage as a facilitator of genome elimination in hybrid cells [102], provides a bridge between the sperm cell defects observed in pollen from haploid inducer lines and paternal specific elimination/loss in embryos [103]. Early evidence supporting the hypothesis of uniparental genome elimination during embryogenesis comes from the observation of micronuclei in putative haploid embryos [99] that are typical of the chromosomal exclusion reported during early embryogenesis of some wide crosses (see chapter 1) [104-106]. Using microsatellite markers, 1$2 \%$ of sorted haploid embryos were deduced to carry paternal genetic information $[36,100,101]$. Three additional studies based on different types of markers as well as different inducer lines and female parents, confirmed the presence of paternal genetic information in putative haploid embryos and showed a high variability from $1 \%$ to $43 \%$ of the embryos $[80,100,101,107]$. Cytological observations also support the paternal genome elimination hypothesis during early embryogenesis (one week after pollination): Performing FISH (Fluorescent In Situ Hybridization) assays, one out of 11 putative haploid embryos was mixoploid (i.e. unbalanced chromosome number between adjacent cells/tissues) with $99 \%$ of the cells being haploid and 1\% diploid [80]. Interestingly, mixoploidy or aneuploidy was also detected in the endosperm of some aborted kernels [80]. These observations suggest that a progressive loss of the paternal inducer genome is occurring in some embryos and endosperms [80]. All the cited evidence leads to the following mechanistic hypothesis (Figure 3; hypothesis 1): anomalies during late pollen development due to mutation of $N L D / M A T L / Z m P L A 1$ lead to chromosome destabilization in one or both sperm cells in a subset of pollen grains. The three main types of pollen all perform normal 
double fertilization leading to normal kernels, defective kernels and kernels with haploid embryos. This last kernel category stems from the situation in which the two sperm cells delivered in the embryo sac have different genome stability: one is normal, the other defective. The first one fuses with the central cell and allows for the development of a normal triploid endosperm, whereas the second one fuses with the egg cell and triggers progressive genome loss and a haploid embryo. Additional observations especially regarding fertilization defects challenged this hypothesis and suggested additional or other mechanisms (see Sections 4.2.3 and 4.2.4).

\subsubsection{Hypothesis of single fertilization}

Numerous aberrant fertilization and fusion events have been described in different maternal haploid inducer germplasms, for example twin embryos, aborted kernels, failure of fertilization, hetero-fertilization and failed egg-sperm cell fusion [74, 97, 98, 108, 109]. Single fertilization of the central cell only, without fertilization of the egg cell, has been hypothesized for a long time to be the event triggering maternal haploid embryos (Figure 3, hypothesis 2) [39]. The high heterofertilization rate observed in different studies using maternal haploid inducer lines may reflect failure of double fertilization and supports the single fertilization hypothesis [98, 108]. Indeed hetero-fertilization is a double fertilization but performed by two distinct sperm cells coming from two different pollen grains [110]. Experiments using two type of pollens (inducer and noninducer pollen) either by pollination with an equal mixture (1/1) [108] or by pollinating at two different time points [98], demonstrated that pollen from haploid inducer lines leads to an average of 3-fold increase of the hetero-fertilization rate as compared to control situations. A heterofertilization rate up to $6.14 \%$ was recorded for some crosses. Interestingly, the heterofertilization rate correlates with the haploid induction rate [98]. In situ observations of fertilized ears by inducer pollen provides a more direct evidence of the existence of single fertilization events: some embryo sacs were found to harbor residual sperm nucleus that did not fuse with egg cell [97]. Tian et al. (2018) also observed division of the central cell without division of the egg cell, which might suggest single fertilization events. To sum-up, single fertilization of the central cell has been hypothesized to be sufficient to trigger egg cell development into a haploid embryo

(Figure 3, hypothesis 2), whereas the symmetric situation in which the egg cell is solely fertilized provides a plausible explanation for a certain level of kernel abortion observed when using haploid inducer lines. However, the recent discovery that maternal haploid embryos can be 
edited via an editing machinery encoded by the paternal inducer line (see Section 2.4) [30, 31], clearly rejects this single fertilization hypothesis, because paternal information must be mandatorily delivered to the egg cell for this to occur [6]. But since not all haploid embryos are edited [30, 31], failure of sperm cell/egg cell fusion could still account for the production of part of the haploid embryos.

\subsubsection{New hypothesis: combination of the two old hypotheses?}

The knowledge gained by the recent identification of two molecular actors underlying maternal haploid induction in maize, opened up the possibility to evaluate haploid induction capacity of molecular players alone or in combination (see Section 4.2.1). This molecular dissection of haploid induction allowed to propose a comprehensive mode of action for haploid embryo production, that combined and revisited the historical hypotheses detailed above [6].

The hypothesis of normal double fertilization, which is followed by paternal genome loss in embryos (Figure 3, hypothesis 1), might reflect the situation occurring in low haploid inducer lines, having $1-3 \%$ of haploid induction rate and carrying only the $n l d /$ matl/zmplal mutation [92, 93]. On the contrary, modern haploid inducer lines with high haploid induction rates (8-12\%) cumulate both $n l d / m a t l / z m p l a l$ and $z m d m p$ mutations [93]. The fact that $z m d m p$ in a context of wild-type $N L D / M A T L / Z m P L A 1$ induces extremely few haploid embryos (see Section 4.2.1), tends to exclude the scenario in which high haploid induction rate would be a consequence of the simple addition of haploid embryos generated from hypotheses 1 (genome loss) and hypothesis 2 (single fertilization). The synergistic effect of $n l d /$ matl/zmplal and zmdmp mutations on haploid induction allows to propose the following new hypothesis (Figure 3, hypothesis 3): the single fertilization event of the central cell is key to generate hetero-fertilization. Then, combining high hetero-fertilization rates with the three types of pollen grains (see Section 4.2.2) offers additional new fertilization contexts that are favorable to the development of supplementary kernels with haploid embryos. One specific case of hetero-fertilization, where central cell single fertilization by a "normal" sperm cell is followed by egg cell fertilization by a sperm cell with chromosome fragmentation, could now be seen as the main mechanism leading to haploid embryos (see Section 4.2.1) [6]. In other words, central cell single fertilization offers a subsequent favorable context for seed development which would reveal haploid embryo induction when a defective sperm cell from another pollen fuses with the egg cell to pursue double fertilization. In contrast, 
in a situation, of no hetero-fertilization (no prior fertilization of the central cell), the arrival of two defective sperm cells would lead to aborted kernels and not to haploid embryo formation. This proposed mechanism remains of course to be experimentally validated, but it allows to revisit the action of single fertilization. Single fertilization could now be viewed as important to generate hetero-fertilizations that boost maternal haploid embryo formation (Figure 3, hypothesis 3) [6]. One thing is certain: maternal haploid induction has now to be seen as a complex process having multiple facets, combining several defects during pollen development, double fertilization and early embryogenesis. Identifying additional molecular players will undoubtedly help to resolve the puzzle.

\section{Concluding remarks}

Maize haploid inducer lines have the advantage to be universal, in the sense that they permit to generate haploid embryos on any given genotype, contrary to most of in vitro methods. Both in planta and in vitro DH technology is currently intensively used to shorten breeding schemes for inbred line development and hybrid seed production [12]. The success of maize haploid inducer lines was made possible by very successful breeding efforts to increase the low induction rate of the original stock-6, together with progress in methods for haploid identification by genetic markers. The limiting step for industrial DH breeding is nowadays the genome doubling method. The genetic variability uncovered for the spontaneous genome doubling trait in maize germplasm might represent a promising starting point for an efficient alternative to present chemical or physical methods of chromosome doubling [68].

Interestingly, identification of molecular players involved in maternal haploid induction has successfully permitted to translate haploid induction capacity to rice [111] and wheat $[112,113]$, expanding in planta haploid induction to additional crops. Further translation to more distant dicotyledonous species seems more delicate due to difficulties to identify the functional orthologs of $N L D / M A T L / Z m P L A 1$ [86]. However, this is not the case for $Z m D M P$, in which clear dicots orthologous genes were found [96]. Interestingly, a mutant impaired in the two Arabidopsis thaliana orthologous genes $A t D M P 8$ and $A t D M P 9$ induces maternal haploid, although at low rate (2\%) [96].This recent discovery could lay the foundations for development of new in planta haploid induction systems in dicotyledonous crops. 


\section{Acknowledgments}

This work was supported by grant "ANR-19-CE20-0012" to T.W, funded by ANR "JC/JC"

(Junior Investigator Grant); and by "pack ambition recherche” from the Région Auvergne-RhoneAlpes ("HD-INNOV”) to T.W. L.M.G and N.M.A.J were supported by CIFRE PhD fellowship from ANRT funding agency, grant no. 2015/0777 and 2019/0771 respectively).

\section{References}

1. Geiger HH, Gordillo GA (2010) Doubled haploids in hybrid maize breeding. 16

2. Chaikam V, Molenaar W, Melchinger AE, Boddupalli PM (2019) Doubled haploid technology for line development in maize: technical advances and prospects. Theor Appl Genet 132:3227-3243 . https://doi.org/10.1007/s00122-019-03433$\mathrm{x}$

3. Blakeslee AF, Farnhama ME, Bergner D, Belling J (1922) A haploid mutant in the jimson weed, "Daturastramonium." Science 55:647-647 . https://doi.org/10.1126/science.55.1433.647

4. Chase SS (1949) Monoploid frequencies in a commercial double cross hybrid maize, and in its component single cross hybrids and inbred lines. Genetics $34: 328$

5. Maluszynski M, Kasha KJ, Szarejko I (2003) Published doubled haploid protocols in plant species. In: Maluszynski M, Kasha KJ, Forster BP, Szarejko I (eds) Doubled Haploid Production in Crop Plants. Springer Netherlands, Dordrecht, pp 309-335

6. Jacquier NMA, Gilles LM, Pyott DE, Martinant J-P, Rogowsky PM, Widiez T (2020) Puzzling out plant reproduction by haploid induction for innovations in plant breeding. Nature Plants. https: / /doi.org/10.1038/s41477-020-0664-9

7. Gilles LM, Martinant J-P, Rogowsky PM, Widiez T (2017) Haploid induction in plants. Current Biology 27:R1095-R1097 . https: / /doi.org/10.1016/j.cub.2017.07.055

8. Kalinowska K, Chamas S, Unkel K, Demidov D, Lermontova I, Dresselhaus T, Kumlehn J, Dunemann F, Houben A (2019) State-of-the-art and novel developments of in vivo haploid technologies. Theor Appl Genet 132:593-605 . https: / doi.org/ 10.1007/s00122-018-3261-9

9. Coe, EH (1959) A Line of Maize with High Haploid Frequency. The American Naturalist 93:381-382 . https://doi.org/10.1086/282098 
10. Kermicle JL (1969) Androgenesis Conditioned by a Mutation in Maize. Science 166:1422-1424 . https://doi.org/10.1126/science.166.3911.1422

11. Chang M-T, Coe EH (2009) Doubled haploids. In: Molecular genetic approaches to maize improvement. Springer, pp 127-142

12. Liu Z, Wang Y, Ren J, Mei M, Frei UK, Trampe B, Lübberstedt T (2016) Maize Doubled Haploids. In: Janick J (ed) Plant Breeding Reviews. John Wiley \& Sons, Inc., Hoboken, NJ, USA, pp 123-166

13. Forster BP, Thomas WTB (2010) Doubled Haploids in Genetics and Plant Breeding. In: Janick J (ed) Plant Breeding Reviews. John Wiley \& Sons, Inc., Oxford, UK, pp 57-88

14. Foiada F, Westermeier P, Kessel B, Ouzunova M, Wimmer V, Mayerhofer W, Presterl T, Dilger M, Kreps R, Eder J, Schön C-C (2015) Improving resistance to the European corn borer: a comprehensive study in elite maize using QTL mapping and genome-wide prediction. Theor Appl Genet 128:875-891 . https: / /doi.org/10.1007/s00122-015-2477-1

15. Tsonev S, Todorovska E, Avramova V, Kolev S, Abu-Mhadi N, Christov NK (2009) Genomics Assisted Improvement of Drought Tolerance in Maize: QTL Approaches. Biotechnology \& Biotechnological Equipment 23:1410-1413 . https: / doi.org/ 10.2478/V10133-009-0004-8

16. Torres AF, Noordam-Boot CMM, Dolstra O, van der Weijde T, Combes E, Dufour P, Vlaswinkel L, Visser RGF, Trindade LM (2015) Cell Wall Diversity in Forage Maize: Genetic Complexity and Bioenergy Potential. Bioenerg Res 8:187-202 . https://doi.org/10.1007/s12155-014-9507-8

17. Lübberstedt T, Frei UK (2012) Application of doubled haploids for target gene fixation in backcross programmes of maize: Doubled haploids for target gene fixation. Plant Breeding 131:449-452 . https://doi.org/10.1111/j.14390523.2011.01948.x

18. Chase SS (1949) Spontaneous Doubling of the Chromosome Complement in Monoploid Sporophytes of Maize. 4

19. Chase SS (1952) Production of Homozygous Diploids of Maize from Monoploids 1. Agronomy Journal 44:263 . https://doi.org/ 10.2134/agronj1952.00021962004400050010x

20. Shull GH (1948) What is" heterosis"? Genetics 33:439

21. Duvick DN (2005) The Contribution of Breeding to Yield Advances in maize (Zea mays L.). In: Advances in Agronomy. Elsevier, pp 83-145

22. Bordes J, Charmet G, de Vaulx RD, Lapierre A, Pollacsek M, Beckert M, Gallais A (2007) Doubled-haploid versus single-seed descent and S1-family variation for testcross performance in a maize population. Euphytica 154:41-51 . https://doi.org/10.1007/s10681-006-9266-5 
23. Weber DF (2014) Today's Use of Haploids in Corn Plant Breeding. In: Advances in Agronomy. Elsevier, pp 123-144

24. Bohra A, Jha UC, Adhimoolam P, Bisht D, Singh NP (2016) Cytoplasmic male sterility (CMS) in hybrid breeding in field crops. Plant Cell Reports 35:967-993

25. Laughnan JR, Gabay-Laughnan S (1983) Cytoplasmic Male Sterility in Maize. Annu Rev Genet 17:27-48 . https://doi.org/10.1146/annurev.ge.17.120183.000331

26. Doudna JA, Charpentier E (2014) The new frontier of genome engineering with CRISPR-Cas9. Science 346:1258096 . https://doi.org/10.1126/science. 1258096

27. Manghwar H, Lindsey K, Zhang X, Jin S (2019) CRISPR/Cas System: Recent Advances and Future Prospects for Genome Editing. Trends in Plant Science 24:1102-1125 . https://doi.org/10.1016/j.tplants.2019.09.006

28. Ji X, Yang B, Wang D (2020) Achieving Plant Genome Editing While Bypassing Tissue Culture. Trends in Plant Science 25:427-429 .

https://doi.org/10.1016/j.tplants.2020.02.011

29. Ikeuchi M, Favero DS, Sakamoto Y, Iwase A, Coleman D, Rymen B, Sugimoto K (2019) Molecular Mechanisms of Plant Regeneration. Annu Rev Plant Biol 70:377-406 . https://doi.org/10.1146/annurev-arplant-050718-100434

30. Wang B, Zhu L, Zhao B, Zhao Y, Xie Y, Zheng Z, Li Y, Sun J, Wang H (2019) Development of a Haploid-Inducer Mediated Genome Editing System for Accelerating Maize Breeding. Molecular Plant 12:597-602 . https: / / doi.org/10.1016/j.molp.2019.03.006

31. Kelliher T, Starr D, Su X, Tang G, Chen Z, Carter J, Wittich PE, Dong S, Green J, Burch E, McCuiston J, Gu W, Sun Y, Strebe T, Roberts J, Bate NJ, Que Q (2019) One-step genome editing of elite crop germplasm during haploid induction. Nat Biotechnol 37:287-292 . https://doi.org/10.1038/s41587-019-0038-x

32. Ishii T, Karimi-Ashtiyani R, Houben A (2016) Haploidization via Chromosome Elimination: Means and Mechanisms. Annu Rev Plant Biol 67:421-438 . https://doi.org/10.1146/annurev-arplant-043014-114714

33. Randolph LF (1932) Some Effects of High Temperature on Polyploidy and Other Variations in Maize. Proceedings of the National Academy of Sciences 18:222229 . https://doi.org/10.1073/pnas.18.3.222

34. Lashermes P, Beckert M (1988) Genetic control of maternal haploidy in maize (Zea mays L.) and selection of haploid inducing lines. Theoret Appl Genetics 76:405-410 . https://doi.org/10.1007/BF00265341

35. Hu H, Schrag TA, Peis R, Unterseer S, Schipprack W, Chen S, Lai J, Yan J, Prasanna BM, Nair SK, Chaikam V, Rotarenco V, Shatskaya OA, Zavalishina A, Scholten S, Schön C-C, Melchinger AE (2016) The Genetic Basis of Haploid 
Induction in Maize Identified with a Novel Genome-Wide Association Method. Genetics 202:1267-1276 . https://doi.org/10.1534/genetics.115.184234

36. Röber FK, Gordillo GA, Geiger HH (2005) In vivo haploid induction in maizeperformance of new inducers and significance of doubled haploid lines in hybrid breeding. Maydica 50:275-283

37. Pollacsek M (1992) Management of the ig gene for haploid induction in maize. Agronomie 12:247-251 . https://doi.org/10.1051/agro:19920304

38. Coe EH, Sarkar KR (1964) The detection of haploids in maize. Journal of Heredity 55:231-233 . https://doi.org/10.1093/oxfordjournals.jhered.a107340

39. Sarkar KR, Coe EH (1966) A genetic analysis of the origin of maternal haploids in maize. Genetics 54:453

40. Smelser A, Blanco M, Lübberstedt T, Schechert A, Vanous A, Gardner C (2015) Weighing in on a method to discriminate maize haploid from hybrid seed. Plant Breed 134:283-285 . https://doi.org/10.1111/pbr.12260

41. Molenaar WS, de Oliveira Couto EG, Piepho H-P, Melchinger AE (2019) Early diagnosis of ploidy status in doubled haploid production of maize by stomata length and flow cytometry measurements. Plant Breeding 138:266-276

42. Lashermes P, Gaillard A, Beckert M (1988) Gynogenetic haploid plants analysis for agronomic and enzymatic markers in maize (Zea mays L.). Theoret Appl Genetics 76:570-572 . https://doi.org/10.1007/BF00260910

43. Dong L, Li L, Liu C, Liu C, Geng S, Li X, Huang C, Mao L, Chen S, Xie C (2018) Genome editing and double-fluorescence proteins enable robust maternal haploid induction and identification in maize. Molecular plant 11:1214-1217

44. Boote BW, Freppon DJ, De La Fuente GN, Lübberstedt T, Nikolau BJ, Smith EA (2016) Haploid differentiation in maize kernels based on fluorescence imaging. Plant Breed 135:439-445 . https://doi.org/10.1111/pbr.12382

45. De La Fuente GN, Carstensen JM, Edberg MA, Lü bberstedt T (2017)

Discrimination of haploid and diploid maize kernels via multispectral imaging. Plant Breed 136:50-60 . https://doi.org/10.1111/pbr.12445

46. Chaikam V, Nair SK, Babu R, Martinez L, Tejomurtula J, Boddupalli PM (2015) Analysis of effectiveness of R1-nj anthocyanin marker for in vivo haploid identification in maize and molecular markers for predicting the inhibition of R1nj expression. Theoretical and applied genetics 128:159-171

47. Chaikam V, Martinez L, Melchinger AE, Schipprack W, Boddupalli PM (2016) Development and validation of red root marker-based haploid inducers in maize. Crop Science 56:1678-1688 
48. Dong X, Xu X, Li L, Liu C, Tian X, Li W, Chen S (2014) Marker-assisted selection and evaluation of high oil in vivo haploid inducers in maize. Molecular breeding 34:1147-1158

49. Rotarenco VA, Kirtoca IH, Jacota AG (2007) The possibility of identifying kernels with haploid embryos using oil content. Maize Genetics Cooperation Newsletter $81: 11$

50. Melchinger AE, Schipprack W, Würschum T, Chen S, Technow F (2013) Rapid and accurate identification of in vivo-induced haploid seeds based on oil content in maize. Sci Rep 3:2129 . https://doi.org/10.1038/srep02129

51. Wang H, Liu J, Xu X, Huang Q, Chen S, Yang P, Chen S, Song Y (2016) Fullyautomated high-throughput NMR system for screening of haploid kernels of maize (Corn) by measurement of oil content. PloS one 11:

52. Melchinger AE, Schipprack W, Mi X, Mirdita V (2015) Oil content is superior to oil mass for identification of haploid seeds in maize produced with high-oil inducers. Crop Science 55:188-195

53. Cui Y, Ge W, Li J, Zhang J, An D, Wei Y (2019) Screening of maize haploid kernels based on near infrared spectroscopy quantitative analysis. Computers and electronics in agriculture 158:358-368

54. Chaikam V, Mahuku G, Prasanna BM (2012) Chromosome doubling of maternal haploids. Doubled haploid technology in maize breeding: Theory and practice 2429

55. Chaikam V, Gowda M, Nair SK, Melchinger AE, Boddupalli PM (2019) Genomewide association study to identify genomic regions influencing spontaneous fertility in maize haploids. Euphytica 215:138

56. Blakeslee AF, Avery AG (1937) Methods of inducing doubling of chromosomes in plants. Journal of Heredity 28:393-411.

https://doi.org/10.1093/oxfordjournals.jhered.a104294

57. Häntzschel KR, Weber G (2010) Blockage of mitosis in maize root tips using colchicine-alternatives. Protoplasma 241:99-104 . https:/ / doi.org/10.1007/s00709-009-0103-2

58. Chaikam V, Gowda M, Martinez L, Ochieng J, Omar HA, Prasanna BM (2020) Improving the Efficiency of Colchicine-Based Chromosomal Doubling of Maize Haploids. Plants 9:459 . https://doi.org/10.3390/plants9040459

59. Melchinger AE, Molenaar WS, Mirdita V, Schipprack W (2016) Colchicine alternatives for chromosome doubling in maize haploids for doubled-haploid production. Crop Science 56:559-569

60. Molenaar WS, Schipprack W, Melchinger AE (2018) Nitrous Oxide-Induced Chromosome Doubling of Maize Haploids. Crop Sci 58:650-659 . https://doi.org/10.2135/cropsci2017.07.0412 
61. Ren J, Wu P, Tian X, Lübberstedt T, Chen S (2017) QTL mapping for haploid male fertility by a segregation distortion method and fine mapping of a key QTL qhmf4 in maize. Theor Appl Genet 130:1349-1359 . https:/ / doi.org/10.1007/s00122-017-2892-6

62. Wu P, Ren J, Tian X, Lübberstedt T, Li W, Li G, Li X, Chen S (2017) New Insights into the Genetics of Haploid Male Fertility in Maize. Crop Science 57:637-647 . https://doi.org/10.2135/cropsci2016.01.0017

63. Yang J, Qu Y, Chen Q, Tang J, Lübberstedt T, Li H, Liu Z (2019) Genetic dissection of haploid male fertility in maize (Zea mays L.). Plant Breeding 138:259-265

64. Kleiber D, Prigge V, Melchinger AE, Burkard F, San Vicente F, Palomino G, Gordillo GA (2012) Haploid fertility in temperate and tropical maize germplasm. Crop science 52:623-630

65. Ren J, A. Boerman N, Liu R, Wu P, Trampe B, Vanous K, Frei UK, Chen S, Lübberstedt T (2020) Mapping of QTL and identification of candidate genes conferring spontaneous haploid genome doubling in maize (Zea mays L.). Plant Science 293:110337 . https://doi.org/10.1016/j.plantsci.2019.110337

66. Wu P, Li H, Ren J, Chen S (2014) Mapping of maternal QTLs for in vivo haploid induction rate in maize (Zea mays L.). Euphytica 196:413-421 . https: / / doi.org/10.1007/s 10681-013-1043-7

67. Trampe B, dos Santos IG, Frei UK, Ren J, Chen S, Lübberstedt T (2020) QTL mapping of spontaneous haploid genome doubling using genotyping-bysequencing in maize (Zea mays L.). Theoretical and Applied Genetics 1-10

68. Boerman NA, Frei UK, Lübberstedt T (2020) Impact of Spontaneous Haploid Genome Doubling in Maize Breeding. Plants 9:369 . https://doi.org/10.3390/plants9030369

69. Dumas C, Rogowsky P (2008) Fertilization and early seed formation. Comptes Rendus Biologies 331:715-725 . https://doi.org/10.1016/j.crvi.2008.07.013

70. Zhou L-Z, Juranić M, Dresselhaus T (2017) Germline Development and Fertilization Mechanisms in Maize. Molecular Plant 10:389-401 . https: / /doi.org/10.1016/j.molp.2017.01.012

71. Faure J-E, Rusche ML, Thomas A, Keim P, Dumas C, Mogensen HL, Rougier M, Chaboud A (2003) Double fertilization in maize: the two male gametes from a pollen grain have the ability to fuse with egg cells. The Plant Journal 33:10511062

72. Kermicle JL (1971) Pleiotropic effects on seed development of the indeterminate gametophyte gene in maize. American Journal of Botany 58:1-7 . https://doi.org/10.1002/j.1537-2197.1971.tb09938.x 
73. Evans MMS (2007) The indeterminate gametophyte 1 Gene of Maize Encodes a LOB Domain Protein Required for Embryo Sac and Leaf Development. Plant Cell 19:46-62 . https://doi.org/10.1105/tpc.106.047506

74. Xu X, Li L, Dong X, Jin W, Melchinger AE, Chen S (2013) Gametophytic and zygotic selection leads to segregation distortion through in vivo induction of a maternal haploid in maize. Journal of experimental botany 64:1083-1096

75. Carputo D, Monti L, Werner JE, Frusciante L (1999) Uses and usefulness of endosperm balance number: Theor Appl Genet 98:478-484 . https://doi.org/10.1007/s001220051095

76. Huang B-Q, Sheridan WF (1996) Embryo Sac Development in the Maize indeterminate gametophytel Mutant: Abnormal Nuclear Behavior and Defective Microtubule Organization. The Plant Cell 8:1391-1407

77. Guo F, Huang B-Q, Han Y, Zee S-Y (2004) Fertilization in maize indeterminate gametophyte1 mutant. Protoplasma 223: . https://doi.org/10.1007/s00709004-0045-7

78. Seguí-Simarro JM (2010) Androgenesis Revisited. Bot Rev 76:377-404 . https: / / doi.org/ 10.1007/s12229-010-9056-6

79. Barret P, Brinkmann M, Beckert M (2008) A major locus expressed in the male gametophyte with incomplete penetrance is responsible for in situ gynogenesis in maize. Theor Appl Genet 117:581-594 . https://doi.org/10.1007/s00122-0080803-6

80. Zhao X, Xu X, Xie H, Chen S, Jin W (2013) Fertilization and Uniparental Chromosome Elimination during Crosses with Maize Haploid Inducers. Plant physiology 163:721-731 . https://doi.org/10.1104/pp.113.223982

81. Bylich VG, Chalyk ST (1996) Existence of pollen grains with a pair of morphologically different sperm nuclei as a possible cause of the haploidinducing capacity in ZMS line. Maize Genetics Cooperation Newsletter 70:33-33

82. Chalyk S (2003) Aneuploidy as a possible cause of haploid-induction in maize. https://mnl.maizegdb.org/mnl/77/15chalyk.html. Accessed 18 Mar 2020

83. Li X, Meng D, Chen S, Luo H, Zhang Q, Jin W, Yan J (2017) Single nucleus sequencing reveals spermatid chromosome fragmentation as a possible cause of maize haploid induction. Nat Commun 8:991 . https://doi.org/10.1038/s41467017-00969-8

84. Prigge V, Xu X, Li L, Babu R, Chen S, Atlin GN, Melchinger AE (2012) New Insights into the Genetics of in Vivo Induction of Maternal Haploids, the Backbone of Doubled Haploid Technology in Maize. Genetics 190:781-793 . https://doi.org/10.1534/genetics.111.133066 
85. Dong X, Xu X, Miao J, Li L, Zhang D, Mi X, Liu C, Tian X, Melchinger AE, Chen S (2013) Fine mapping of qhir1 influencing in vivo haploid induction in maize.

Theoretical and applied genetics 126:1713-1720

86. Gilles LM, Khaled A, Laffaire J, Chaignon S, Gendrot G, Laplaige J, Bergès H, Beydon G, Bayle V, Barret P, Comadran J, Martinant J, Rogowsky PM, Widiez T (2017) Loss of pollen-specific phospholipase NOT LIKE DAD triggers gynogenesis in maize. EMBO J 36:707-717 . https://doi.org/10.15252/embj.201796603

87. Kelliher T, Starr D, Richbourg L, Chintamanani S, Delzer B, Nuccio ML, Green J, Chen Z, McCuiston J, Wang W, Liebler T, Bullock P, Martin B (2017)

MATRILINEAL, a sperm-specific phospholipase, triggers maize haploid induction. Nature 542:105-109 . https://doi.org/10.1038/nature20827

88. Liu C, Li X, Meng D, Zhong Y, Chen C, Dong X, Xu X, Chen B, Li W, Li L, Tian X, Zhao H, Song W, Luo H, Zhang Q, Lai J, Jin W, Yan J, Chen S (2017) A 4-bp Insertion at ZmPLA1 Encoding a Putative Phospholipase A Generates Haploid Induction in Maize. Molecular Plant 10:520-522 .

https: / doi.org/10.1016/j.molp.2017.01.011

89. Scherer GFE, Ryu SB, Wang X, Matos AR, Heitz T (2010) Patatin-related phospholipase A: nomenclature, subfamilies and functions in plants. Trends in Plant Science 15:693-700 . https://doi.org/10.1016/j.tplants.2010.09.005

90. Murakami M, Taketomi Y, Miki Y, Sato H, Hirabayashi T, Yamamoto K (2011) Recent progress in phospholipase A2 research: From cells to animals to humans. Progress in Lipid Research 50:152-192 .

https://doi.org/10.1016/j.plipres.2010.12.001

91. Wang X (2001) Plant phospholipases. Annual review of plant biology 52:211-231

92. Liu C, Li W, Zhong Y, Dong X, Hu H, Tian X, Wang L, Chen B, Chen C, Melchinger AE, Chen S (2015) Fine mapping of qhir8 affecting in vivo haploid induction in maize. Theor Appl Genet 128:2507-2515 . https: / doi.org/10.1007/s00122-015-2605-y

93. Zhong Y, Liu C, Qi X, Jiao Y, Wang D, Wang Y, Liu Z, Chen C, Chen B, Tian X, Li J, Chen M, Dong X, Xu X, Li L, Li W, Liu W, Jin W, Lai J, Chen S (2019) Mutation of ZmDMP enhances haploid induction in maize. Nat Plants 5:575-580 . https://doi.org/10.1038/s41477-019-0443-7

94. Cyprys P, Lindemeier M, Sprunck S (2019) Gamete fusion is facilitated by two sperm cell-expressed DUF679 membrane proteins. Nat Plants 5:253-257 . https://doi.org/10.1038/s41477-019-0382-3

95. Takahashi T, Mori T, Ueda K, Yamada L, Nagahara S, Higashiyama T, Sawada H, Igawa $\mathrm{T}$ (2018) The male gamete membrane protein DMP9/DAU2 is required for double fertilization in flowering plants. Development 145:dev170076 . https://doi.org/10.1242/dev.170076 
96. Zhong Y, Chen B, Li M, Wang D, Jiao Y, Qi X, Wang M, Liu Z, Chen C, Wang Y, Chen M, Li J, Xiao Z, Cheng D, Liu W, Boutilier K, Liu C, Chen S (2020) A DMPtriggered in vivo maternal haploid induction system in the dicotyledonous Arabidopsis. Nat Plants 6:466-472 . https://doi.org/10.1038/s41477-020-06587

97. Swapna M, Sarkar KR (2011) Anomalous fertilization in haploidy inducer lines in maize (Zea mays L). 6

98. Tian X, Qin Y, Chen B, Liu C, Wang L, Li X, Dong X, Liu L, Chen S (2018) Heterofertilization together with failed egg-sperm cell fusion supports single fertilization involved in in vivo haploid induction in maize. Journal of Experimental Botany 69:4689-4701 . https://doi.org/10.1093/jxb/ery 177

99. Wedzony M, Röber FK, Geiger HH (2002) Chromosome elimination observed in selfed progenies of maize inducer line RWS. In: XVIIth International Congress on Sex Plant Reports Maria Curie--Sklodowska University Press, Lublin

100. Fischer E (2004) Molecular genetic studies on the occurrence of paternal DNA transmission during in vivo haploid induction in maize (Zea mays). Dissertation, University of Hohenheim

101. Zhang Z, Qiu F, Liu Y, Ma K, Li Z, Xu S (2008) Chromosome elimination and in vivo haploid production induced by Stock 6-derived inducer line in maize (Zea mays L.). Plant Cell Rep 27:1851-1860 . https://doi.org/10.1007/s00299-0080601-2

102. Wang Z, Yin H, Lv L, Feng Y, Chen S, Liang J, Huang Y, Jiang X, Jiang H, Bukhari I, Wu L, Cooke HJ, Shi Q (2014) Unrepaired DNA damage facilitates elimination of uniparental chromosomes in interspecific hybrid cells. Cell Cycle $13: 13$

103. Comai L, Tan EH (2019) Haploid Induction and Genome Instability. Trends in Genetics 35:791-803 . https://doi.org/10.1016/j.tig.2019.07.005

104. Bennett MD, Finch RA, Barclay IR (1976) The time rate and mechanism of chromosome elimination in Hordeum hybrids. Chromosoma 54:175-200 . https:/ / doi.org/10.1007/BF00292839

105. Devaux P (2003) The Hordeum bulbosum (L.) method. In: Maluszynski M, Kasha KJ, Forster BP, Szarejko I (eds) Doubled Haploid Production in Crop Plants. Springer Netherlands, Dordrecht, pp 15-19

106. Gernand D, Rutten T, Pickering R, Houben A (2006) Elimination of chromosomes in Hordeum vulgare $\times H$. bulbosum crosses at mitosis and interphase involves micronucleus formation and progressive heterochromatinization. Cytogenet Genome Res 114:169-174 . https://doi.org/10.1159/000093334

107. Li L, Xu X, Jin W, Chen S (2009) Morphological and molecular evidences for DNA introgression in haploid induction via a high oil inducer CAUHOI in maize. Planta 230:367-376 . https://doi.org/10.1007/s00425-009-0943-1 
108. Rotarenco V, Eder J (2003) Possible effects of heterofertilization on the induction of maternal haploids in maize. Maize Genetics Cooperation Newsletter 77:30-30

109. Liu L, Li W, Liu C, Chen B, Tian X, Chen C, Li J, Chen S (2018) In vivo haploid induction leads to increased frequency of twin-embryo and abnormal fertilization in maize. BMC plant biology 18:313

110. Sprague GF (1932) The nature and extent of hetero-fertilization in maize. Genetics 17:358

111. Yao L, Zhang Y, Liu C, Liu Y, Wang Y, Liang D, Liu J, Sahoo G, Kelliher T (2018) OsMATL mutation induces haploid seed formation in indica rice. Nature Plants 4:530-533 . https://doi.org/10.1038/s41477-018-0193-y

112. Liu C, Zhong Y, Qi X, Chen M, Liu Z, Chen C, Tian X, Li J, Jiao Y, wang D, Wang Y, Li M, Xin M, Liu W, Jin W, Chen S (2019) Extension of the in vivo haploid induction system from maize to wheat. Plant Biology

113. Liu H, Wang K, Jia Z, Gong Q, Lin Z, Du L, Pei X, Ye X (2020) Efficient induction of haploid plants in wheat by editing of TaMTL using an optimized Agrobacterium-mediated CRISPR system. Journal of Experimental Botany 71:1337-1349 . https://doi.org/10.1093/jxb/erz529 


\section{Figure legends}

Figure 1. Overview of DH scheme using maize in planta haploid induction. Schematic presentation of DH technology in maize. Maize haploid kernels with haploid embryo are first generated thanks to in planta haploid induction. They are then sorted among the normal kernels before being processed for genome doubling to obtain pure homozygous DH lines.

Figure 2. Rapid inbred line development using maize in planta maternal haploid inducer lines. Both single seed descent (SSD) scheme and DH scheme start with plants having interesting traits with high heterozygosity. Inbred line production using the single seed descent (SSD) scheme consists of several runs of self-fertilization of the individuals of interest. In comparison to DH scheme, the SSD method is longer in time and derived inbred lines can still have residual heterozygosity. For the DH scheme, pollen from a haploid inducer line is used for a cross with a plant with high heterozygosity, used as female. About 5-10\% of the developed kernels will carry haploid embryos of maternal origin. Each haploid embryo has a different maternal chromosome/gene combination. After haploid identification and chromosome doubling, selfing the fertile plants results in homogeneous progeny of homozygous DH plants.

Figure 3. Hypothetical mechanisms behind maize in planta maternal haploid induction. Different hypotheses to explain seed-based maternal haploid embryo induction in maize. Anomalies during pollen development lead to at least three types of pollen grains with different genomic integrity in sperm cells (upper right) [83]. Germination on pollen grains on female silks allows pollen tubes to reach embryo sacs to release sperm cell pair. In normal double fertilization (the majority of cases), the sperm cell/egg cell fusion gives rise to the diploid embryo, and the parallel sperm cell/central cell fusion gives rise to the triploid endosperm (nourishing tissue). Hypothesis 1 speculates that double fertilization occurs, but that only one of the three possible pollen grains would induce a haploid embryo, i. e. when an aneuploid sperm cell fuses with the egg cell, whereas the normal paired sperm cell fuses with the central cell. This would lead to progressive loss of paternal genome only in the embryo, whereas the endosperm develops correctly, ensuring the production of a well-developed kernel with a haploid embryo. Hypothesis 2 speculates that 
the single fertilization of the central cell by a normal sperm cell would be sufficient to trigger autonomous development of the haploid egg cell into a haploid embryo. Recent insight into the molecular actors that control maternal haploid induction (see Section 4.2.1) not only confirms each of the two hypotheses individually but also suggests a synergistic combination, hypothesis 3, whereby single fertilization could be followed by hetero-fertilization, allowing a second pollen tube to deliver new pairs of sperm cells. In the case of a defective sperm cell, this would offer additional possibilities to be in the favorable situation depicted for hypothesis 1 (see Section 4.2.4). This unified hypothesis is supported by the observation that double mutants for the molecular players have synergistic effects. Please note that this diagram is not exhaustive and depicts only the most interesting cases. 